\title{
Editorial
}

Simon Hales*

\section{Climate change, extreme rainfall events, drinking water and enteric disease}

https://doi.org/10.1515/reveh-2019-2001

Recent extreme climatic events show how vulnerable modern societies are to climate variability. Storms, droughts, heatwaves, fires and floods and their often severe effects on affected populations are documented every day in global media. In this editorial, I outline evidence linking extreme rainfall events, water quality and enteric disease, and ask how this evidence might be applied to better understanding of the impacts of climate change.

In New Zealand, a major outbreak of campylobacteriosis was recently linked to contamination of a local water supply following heavy rainfall. This was the largest recorded outbreak of water-borne disease in New Zealand (and probably for water-borne campylobacteriosis in the world) resulting in an estimated 5500 cases, 45 hospitalisations and three deaths. It triggered a major official inquiry which generated two substantial reports and recommendations for a major overhaul of New Zealand's drinking water system (1). The Inquiry noted that: "Drinking water contamination has the potential to affect extraordinarily large numbers of people and to cause harm at a level which is extremely serious to individuals, communities, businesses, New Zealand's tourism industry and to society as a whole" (1). The Inquiry highlighted the importance of the multi-barrier approach to prevention of water-borne disease, and noted events such as extreme weather that challenge the treatment process are important warning signs of potential contamination.

Internationally, research is now filling in the connections between climate change, altered rainfall patterns, rising temperatures and health outcomes $(2,3)$. While it is difficult to quantify precisely effects of climate change on rainfall, observed climate trends are consistent with the projected effects. The frequency and/or intensity of extreme rainfall events is projected to increase (4). However, attempts to quantify the potential effects of global climate change on enteric disease have so far accounted for effects of increasing temperature, but not rainfall. The main reason for this is the heterogeneity of rainfall effects in different settings, making extrapolation of these results to potential future impacts difficult.

The role of weather and climate factors in waterborne infections has recently been reviewed. A total of 24 studies were identified between 2001 and 2013, mainly from Asia and North America (5). Most studies reported a positive association between increased temperature or rainfall and enteric infection, after a variable lag period. Six studies reported no significant association between rainfall and enteric disease, while two studies reported positive associations with both increased and reduced rainfall. The authors recommended further studies “...examining potential effect modifiers, such as the specific type of microorganism, geographical region, season, type of water supply, water source or water treatment, in order to assess how they modulate the relationship between heavy rain events or temperature and waterborne disease" (5). A subsequent case-control study in the Nordic countries found that extreme rainfall events were significantly associated with the occurrence of enteric disease outbreaks (6).

A review of time series studies of water treatment plant parameters and enteric disease focussed on urban areas in developed countries (7). A significant association between turbidity (or particle count) in supplied water and enteric disease was reported in 11 of 17 sites, but the strength of the association varied by site. Water temperature, river flow, and water supply flow were significant risk factors for enteric disease (7). A time series study of weather, water quality and enteric disease in France and Spain also reported site-specific associations with turbidity, especially after runoff events following a dry period (8). This study used prescription reimbursements as a proxy for enteric disease, which they estimated might account for about a third of enteric disease cases treated at home.

A review of the relationships between groundwater contamination and outbreaks of acute gastrointestinal infection (enteric disease) identified 649 studies globally (9). The authors estimated that between 35 and 59 million cases of enteric disease were attributable to the consumption of groundwater annually. The main pathogens 
identified were Campylobacter, Shigella, hepatitis A, Giardia and norovirus. Cryptosporidiosis has also been the cause of several large outbreaks $(3,10)$.

In New Zealand, associations between climate and enteric disease have been analysed in several studies, including a descriptive study (11), time series studies (10, $12,13)$, a spatial study (12) and in spatio-temporal analyses $(14,15)$. Results to date have not always been consistent, but there are indications that some enteric diseases caused by specific pathogens are sensitive to climate factors. For example, in a spatial study of small areas (census area units), there was a positive association between rainfall and cryptosporidiosis and the effect of rainfall was modified by the quality of the domestic water supply (12).

Historically, New Zealand has experienced high rates of enteric disease in comparison to similar countries (16-18). This elevated risk may be related, in part, to high numbers of livestock. Studies have reported positive associations between cryptosporidiosis and livestock densities $(14,17)$. Another relevant factor is low population density, which makes it difficult to provide community drinking water supplies of high quality. Only about twothirds of the New Zealand population has access to water supplies that meet the drinking water standards. Meeting the standards does not guarantee safety, but makes it less likely there will be major disruption following unusual events such as heavy rain, droughts, power failures, or organisational failures.

Future estimates of the impact of climate change on drinking water quality and enteric disease should attempt to incorporate estimates of the potential impacts of changes in rainfall as well as temperature. This will require better understanding of contextual modifying effects on observed climate-health associations. Where available, water quality data might act as a useful proxy for the effect of climate variability on pathogen exposure. In turn, although not pathogen specific, prescription data may be a good proxy for enteric disease incidence. Published studies often report overall associations between climate variability and enteric disease, without exploring potential effect modification (e.g. (19)). Where time series of enteric disease and climate data are available for multiple subnational regions, future studies should reanalyse these data along with subnational covariates such as land use, hydrology, type of water supply, water sources and water treatment, sanitation and socio-economic factors.

Acknowledgement: I thank Michael Baker, Nick Wilson and Alistair Woodward for helpful comments and discussions.

\section{References}

1. NZ Government. Government Inquiry into Havelock North Drinking Water. Wellington; 2017.

2. Ebi K, Ogden N, Semenza J, Woodward A. Detecting and attributing health burdens to climate change. Environ Health Perspect 2017:125:085004.

3. Levy K, Smith SM, Carlton EJ. Climate change impacts on waterborne diseases: moving toward designing interventions. Curr Environ Health Rep 2018;5(2):272-82.

4. Barros VR, Field CB, Dokken DJ, Mastrandrea MD, Mach KJ, Bilir TE, et al. Climate Change 2014: impacts, adaptation, and vulnerability. Contribution of Working Group II to the Fifth Assessment Report of the Intergovernmental Panel on Climate Change. Cambridge, UK: Cambridge University Press; 2014.

5. Guzman Herrador BR, de Blasio BF, MacDonald E, Nichols G, Sudre B, Vold L, et al. Analytical studies assessing the association between extreme precipitation or temperature and drinking water-related waterborne infections: a review. Environ Health 2015;14:29.

6. Guzman Herrador B, de Blasio BF, Carlander A, Ethelberg S, Hygen HO, Kuusi M, et al. Association between heavy precipitation events and waterborne outbreaks in four Nordic countries, 1992-2012. J Water Health 2016;14(6):1019-27.

7. Beaudeau P. A systematic review of the time series studies addressing the endemic risk of acute gastroenteritis according to drinking water operation conditions in urban areas of developed countries. Int J Environ Res Public Health 2018;15(5):867.

8. Setty KE, Enault J, Loret J-F, Puigdomenech Serra C, MartinAlonso J, Bartram J. Time series study of weather, water quality, and acute gastroenteritis at Water Safety Plan implementation sites in France and Spain. Int J Hyg Environ Health 2018;221(4):714-26.

9. Murphy HM, Prioleau MD, Borchardt MA, Hynds PD. Review: epidemiological evidence of groundwater contribution to global enteric disease, 1948-2015. Hydrogeol J 2017;25(4):981-1001.

10. Lal A, Ikeda T, French N, Baker MG, Hales S. Climate variability, weather and enteric disease incidence in New Zealand: time series analysis. PLoS One 2013;8(12):e83484.

11. Lal A, Hales S, French N, Baker MG. Seasonality in human zoonotic enteric diseases: a systematic review. PLoS One 2012;7(4):e31883.

12. Britton E, Hales S, Venugopal K, Baker MG. The impact of climate variability and change on cryptosporidiosis and giardiasis rates in New Zealand. J Water Health 2010;8(3):561-71.

13. Lal A, Hales S, Kirk M, Baker MG, French NP. Spatial and temporal variation in the association between temperature and salmonellosis in NZ. Aust N Z J Public Health 2016;40(2):165-9.

14. Lal A, Marshall J, Benschop J, Brock A, Hales S, Baker M, et al. A Bayesian spatio-temporal framework to identify outbreaks and examine environmental and social risk factors for infectious diseases monitored by routine surveillance. Spat Spatiotemporal Epidemiol 2018;25:39-48.

15. Spencer S, Marshall J, Pirie R, Campbell D, French N. The detection of spatially localised outbreaks in 
campylobacteriosis notification data. Spat Spatiotemporal Epidemiol 2011;2:173-83.

16. Baker MG, Sneyd E, Wilson NA. Is the major increase in notified campylobacteriosis in New Zealand real? Epidemiol Infect 2007;135(1):163-70.

17. Snel SJ, Baker MG, Kamalesh V, French N, Learmonth J. A tale of two parasites: the comparative epidemiology of cryptosporidiosis and giardiasis. Epidemiol Infect 2009;137(11):1641-50.
18. Lal A, Baker MG, French NP, Dufour M, Hales S. The epidemiology of human salmonellosis in New Zealand, 1997-2008. Epidemiol Infect 2011;140(9):1685-94.

19. Wangdi K, Clements AC. Spatial and temporal patterns of diarrhoea in Bhutan 2003-2013. BMC Infect Dis 2017;17(1):507.

* Corresponding author: Simon Hales, Department of Public Health, University of Otago, Wellington, New Zealand,

E-mail: simon.hales@otago.ac.nz 